\title{
Inadequate harvest of internal mammary artery—beware!
}

\author{
Ramkumar Jayavelan • Richard Saldanha • Dheeraj Reddy • \\ Jayanti Shri Sathyanarayana Moorthy
}

Received: 23 September 2012 /Revised: 28 October 2012 / Accepted: 18 December 2012 /Published online: 7 February 2013

(C) Indian Association of Cardiovascular-Thoracic Surgeons 2013

Internal Thoracic Artery (ITA) has been universally accepted as a superior conduit for patients undergoing coronary artery bypass operations. Hence, ITA harvest must be done with utmost care. All the branches of ITA must be clipped to ensure a long term patency. Sometimes, one encounters an ITA densely adherent to the overlying periosteum often prompting the surgeon to leave behind unclipped branches. The surgeon must be aware that there is a $15 \%$ incidence of lateral costal branch in internal thoracic arteries [1], which can sometimes be overlooked.

Coronary angiogram in a symptomatic patient, who underwent coronary artery bypass grafting 2 years ago, showed a prominent unclipped lateral costal branch from Left Internal Thoracic Artery (LITA) and string sign of LITA (Fig. 1). This case demonstrates the importance of complete harvest and clipping of all the branches of LITA for its patency.

R. Jayavelan $\cdot$ R. Saldanha $\cdot$ D. Reddy

Department of Cardiothoracic Surgery, Sri Ramachandra

University, Porur, Chennai 600116 Tamil Nadu, India

\section{J. S. S. Moorthy}

Department of Cardiology, Sri Ramachandra University, Porur,

Chennai 600116 Tamil Nadu, India

R. Jayavelan $(\bowtie)$

No-5, Jayanthi street, Dr.Seethapathi nagar,

Chennai 600042 Tamil Nadu, India

e-mail: drjramkumar@yahoo.co.in

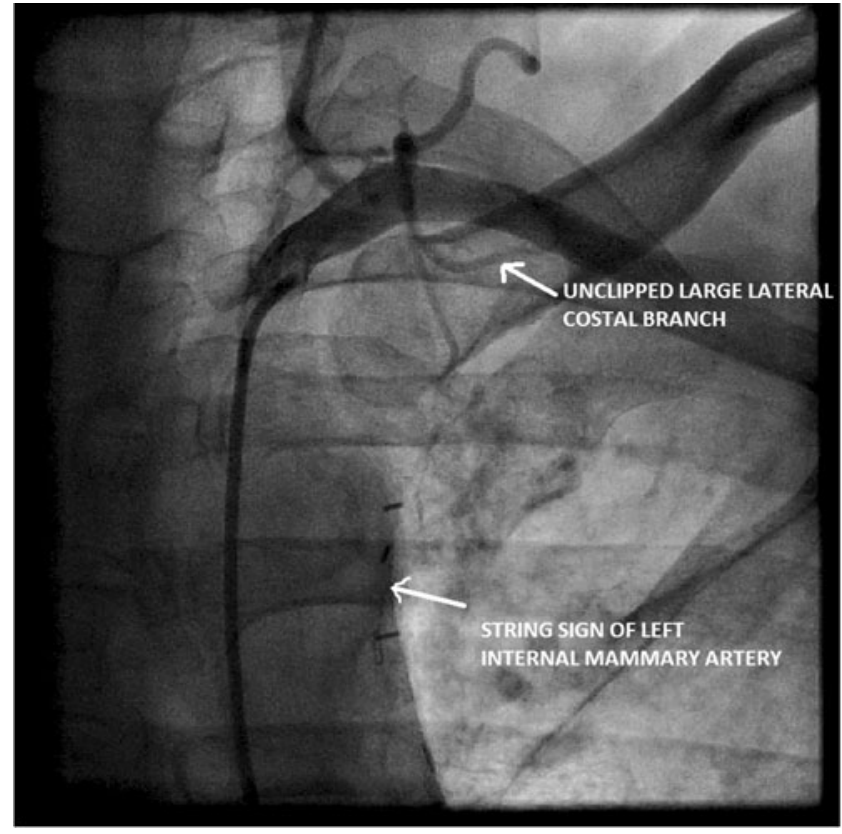

Fig. 1 Coronary angiogram demonstrating an unclipped large lateral costal branch of left internal mammary artery (arrow) and string sign of left internal thoracic artery (arrow)

\section{Reference}

1. Henriquez-Pino JA, Gomes WJ, Prates JC, Buffolo E. Surgical anatomy of the internal thoracic artery. Ann Thorac Surg. 1997;64:1041-5. 